\title{
GÊNEROS INTRODUTÓRIOS EM AMBIENTE VIRTUAL: UMA (RE) ANÁLISE DOS PROPÓSITOS COMUNICATIVOS
}

Benedito Gomes Bezerra*

\begin{abstract}
Resumo: Neste trabalho, reexaminamos o conceito de propósito comunicativo, oriundo da análise de gêneros de linha sociorretórica, tendo em conta os gêneros introdutórios de livros acadêmicos realizados em meio digital. A pesquisa, fundamentada teoricamente nas obras de Swales (1990, 2004), Bhatia (1997a, 2004) e Bezerra (2006), investiga um corpus de 50 exemplares de gêneros introdutórios digitais recolhidos de sites de editoras e livrarias especializadas. Os resultados mostram que os gêneros em questão, ao serem transportados do meio impresso para o suporte virtual, passam por sensíveis transformações em seus propósitos comunicativos. Particularmente, o discurso acadêmico típico desses gêneros tende a dar lugar a um discurso marcadamente promocional, caracterizando um processo de colonização de gêneros por outros gêneros e discursos (BHATIA, 2004).

Palavras-chave: hipertexto; gênero introdutório; propósito comunicativo.
\end{abstract}

\section{INTRODUÇÃO}

Para o analista de gêneros textuais interessado na pesquisa de gêneros digitais, diversas questões se apresentam como desafios incontornáveis. Entre elas, dois aspectos essenciais entram imediatamente em foco: os propósitos comunicativos e o suporte. Não é de se esperar que um determinado gênero, ao ser transportado do meio impresso convencional ou da fala para o ambiente da web, se mostre

\footnotetext{
* Professor da Universidade de Pernambuco (UPE), Recife, Pernambuco, Brasil. Doutor em Linguística. Email: <beneditobezerra@yahoo.com.br>.
} 
“indiferente ao suporte” (MARCUSCHI, 2003), ou que seus propósitos comunicativos não sejam ressignificados na nova situação comunicativa.

A noção de suporte, por sua vez, sempre uma questão debatida na análise de gêneros da fala e escrita tradicionais, volta a ser uma interrogação importante no contexto da introdução dos novos suportes textuais baseados nas mídias eletrônicas. A pergunta central é até que ponto a alteração no suporte conduz a mudanças significativas no gênero. Lembremos, a propósito disso, dos ditos célebres de Maingueneau (2001, p. 68), para quem "uma modificação do suporte material de um texto modifica radicalmente um gênero do discurso", e de Marcuschi (2003, p. 10), para quem o suporte "é imprescindível para que o gênero circule na sociedade e deve ter alguma influência na natureza do gênero suportado [...] pois há casos complexos em que o suporte determina a distinção que o gênero recebe".

Diante dessas considerações, o objetivo deste artigo é essencialmente oferecer subsídios para uma resposta à questão: qual é o status dos propósitos comunicativos em gêneros textuais transmutados para a web? Dito de outra forma, os propósitos comunicativos de um gênero atualizado em suporte impresso se mantêm quando esse gênero é apresentado no ambiente web ou sofrem algum tipo de transformação?

Para tentar responder a essas interrogações, apresentarei exemplos de análise de gêneros digitais introdutórios em livros acadêmicos divulgados pela $w_{e} b^{1}$, tomando como modelo de análise a proposta de Askehave e Nielsen (2004), cujas linhas gerais serão esboçadas adiante. Antes, porém, examinaremos mais detidamente os conceitos de propósito comunicativo e suporte, além de fazer algumas reflexões sobre o status da leitura em hipertexto.

\section{O(S) PROPÓSITO(S) COMUNICATIVO(S)}

Para muitos estudiosos da área, a noção de propósito comunicativo apresenta-se como um dos conceitos centrais para a compreensão da construção, interpretação e uso dos gêneros, mesmo

\footnotetext{
${ }^{1}$ Para uma análise dos gêneros textuais introdutórios em suporte impresso, ver minha tese de doutoramento (BEZERRA, 2006).
}

BEZERRA - Gêneros introdutórios em ambiente virtual... 
quando nem todos os estudiosos se utilizam dessa terminologia. Assim é que Miller (1984), representando o ponto de vista da nova retórica, já enfatizava que os gêneros devem ser definidos preferencialmente pela ação retórica que realizam, e não por sua forma ou substância. Estabelecendo uma definição que nortearia todo o trabalho da chamada Escola de Sydney, Martin afirma que os gêneros são "uma atividade gradativa, direcionada para um objetivo e dotada de um propósito, na qual, como membros de uma cultura, os falantes se engajam" (1984, p. 25). Na perspectiva baseada na obra de Swales (1990, p. 58), o gênero "compreende uma classe de eventos comunicativos cujos membros compartilham um conjunto de propósitos comunicativos". Conforme ressaltam Kay e Dudley-Evans (1998, p. 308), tanto para Martin como para Swales, é o propósito comunicativo que realmente faz surgir o gênero, "moldando a estrutura 'esquemática' ou 'começo-meio-fim' do discurso e influenciando nas escolhas de conteúdo e de estilo".

Seguindo a perspectiva swalesiana, Bhatia (1993, p. 13) considera que, em sua natureza e construção, o gênero "é caracterizado essencialmente pelo(s) propósito(s) comunicativo(s) que pretende realizar", embora seja influenciado também por fatores tais como conteúdo, forma, audiência, meio ou canal. Na opinião de Bhatia, a relação entre gênero e propósito comunicativo é tão próxima e central que se pode conceber o gênero como "um exemplo da realização bemsucedida de um determinado propósito comunicativo, utilizando o conhecimento convencionado de recursos linguísticos e discursivos" (1993, p. 16). Dessa forma, mudanças mais radicais nos propósitos comunicativos resultam na construção de gêneros diferentes. A manifestação de um propósito comunicativo comum não implica, naturalmente, uma rigidez estrutural na construção dos gêneros. A maleabilidade, traço constitutivo da produção e circulação dos gêneros, em si não invalida a sua identificação através de propósitos comunicativos específicos. As variações verificáveis em textos que pertencem ao mesmo gênero são bem explicadas e podem ser entendidas a partir da noção de prototipicidade proposta por Swales (1990, p. 49), bem como através da ideia de "relativa estabilidade" apresentada por Bakhtin (1953).

Entretanto, nem sempre fica claro o que se quer dizer com a expressão "propósito comunicativo" (communicative purpose). Seria ele 
equivalente a noções como função ou intenção (do texto ou do autor), por exemplo, ou corresponde mais proximamente a conceitos como objetivo, meta e finalidade? Examinando a literatura a respeito, provavelmente não encontraremos uma definição do tipo "propósito comunicativo é...", mas apenas alusões diversas das quais podemos tentar inferir uma conceituação. Em Swales (1990), por exemplo, encontramos que atribuir ao propósito comunicativo o papel de critério privilegiado na constituição dos gêneros implica pressupor que, "a não ser por alguns casos interessantes e excepcionais, os gêneros são veículos comunicativos para a realização de objetivos (goals)" (p. 46).

Nesse sentido, encontramos também em Askehave e Swales (2001) a conceituação de gêneros como "orientados para objetivos ou dotados de propósitos (goal-directed or purposive)". Essa mesma conceituação é adotada por Atkinson (1999). Central na argumentação desses autores, entre os quais ainda se poderia citar Bhatia (1997b) e Johns (1997), entre outros, é a premissa de que os gêneros são sempre utilizados para realizar alguma coisa no interior das mais diversas formas de práticas sociais. Nesse contexto, a noção de propósito comunicativo é apresentada como parte de uma concepção funcional de gêneros, por oposição a uma visão meramente formal. Entretanto, o termo função não é utilizado nem tomado como equivalente a propósito comunicativo (ASKEHAVE; NIELSEN, 2004).

Neste sentido, o propósito comunicativo tem a ver exatamente com aquilo que os gêneros realizam na sociedade, admitindo-se, porém, que o propósito de um gênero não é necessariamente único e predeterminado. No conjunto de propósitos comunicativos realizados por um gênero, haverá propósitos específicos ou "intenções particulares" de certos atores sociais, sejam eles os produtores do gênero ou os controladores de sua produção e circulação, como no caso dos gêneros da mídia, por exemplo, ao lado dos propósitos "socialmente reconhecidos" (BHATIA, 1993, 1997b).

O propósito comunicativo, portanto, não será algo simplesmente imanente no texto como tal, visto que se trata sempre de um processo de construção social desse propósito ou propósitos, nem será uma realidade meramente psicológica, definível como "intenção do autor", pois seria imperativo questionar essa onipotência do autor sobre o texto e sua recepção na sociedade. Por outro lado, reconhecendo-se que os gêneros, 
inseridos como são em complexas práticas sociais, não são produzidos de forma neutra e desinteressada, é bem possível falar de intenções públicas e intenções escamoteadas, como o faz Bhatia (1993, 1997b). "Intenções", nesse caso, de atores e grupos sociais, e não dos textos em si, o que não implica uma concepção meramente psicologizante de propósito comunicativo.

Dentro disso, compreende-se a reticência de Swales (2004, p. 68) em admitir a viabilidade de se analisar tais "intenções particulares" como fenômeno psicológico. Para ele, deve-se ressaltar a dimensão social dos propósitos comunicativos. Curiosamente, o exemplo do gênero carta de recomendação que Swales trabalha em seguida aponta para propósitos comunicativos essencialmente "particulares", ao lado dos propósitos socialmente reconhecidos, sejam lá quais forem esses. De modo que, conforme Swales, "talvez pudéssemos concluir que esses propósitos na verdade são múltiplos” (2004, p. 71).

De toda forma, essas intenções "particulares", que não correspondem univocamente ao conceito de propósito comunicativo, de fato existem lado a lado com os propósitos "socialmente reconhecidos", e poderão ser mais ou menos bem-sucedidas na realização de um dado exemplar de gênero, mas diversos outros fatores deverão ser considerados. Um deles seria: até que ponto o artefato genérico efetivamente construído corresponderá à intenção psicológica de seu autor?

Depois de assumir, sem desenvolvê-lo exaustivamente, o conceito de propósito comunicativo como "critério privilegiado" e "prototípico" para a identificação dos gêneros (SWALES, 1990), mais recentemente Swales (2004) retoma o conceito a partir da discussão apresentada em Askehave e Swales (2001), em que a noção de propósito comunicativo é apresentada sob nova luz, sendo submetida a uma profunda reformulação. $\mathrm{Na}$ referida obra, os autores verificam que os propósitos comunicativos frequentemente são "mais evasivos, múltiplos, intricados e complexos do que foi originalmente imaginado" (ASKEHAVE; SWALES, 2001, p. 197). Em nome do propósito comunicativo, o analista não deverá deduzir uma identificação apriorística dos gêneros, pois somente a investigação mais apurada, incluindo "o contexto em que o texto é usado" (p. 203), poderá conduzir a uma descrição realista dos seus propósitos. O propósito comunicativo se encontra, portanto, não 
no início da análise, mas "ao se completar o círculo hermenêutico" (p. 210). Assim, Askehave e Swales (2001, p. 200) apresentam três sugestões para a utilização do conceito de propósito comunicativo na análise de gêneros: (1) Ele pode ter um "valor heurístico" como porta de entrada para a melhor compreensão de um corpus de textos; (2) Ele pode ajudar a mostrar que os discursos eventualmente são multifuncionais; e (3) Ele pode ser usado para desqualificar o status de gênero atribuído a certos domínios discursivos, tal como o "economês", às vezes baseados apenas na rotulação de certos registros.

Contudo, mesmo levando-se em conta as variadas discussões sobre o assunto, o propósito comunicativo permanece potencialmente como um "conceito-chave" para a análise de gêneros (ASKEHAVE; SWALES, 2001, p. 200). De fato, experiências de pesquisas anteriores mostram que o conceito de propósito comunicativo ainda pode ser produtivamente explorado na análise de gêneros diversos. Um exemplo disso, relacionado com a análise de resenhas acadêmicas, se encontra em Bezerra (2001). Entretanto, somente podemos falar de "identificação" de gêneros com base em seu propósito comunicativo a partir de uma análise mais ampla, nunca como uma categorização a priori.

De acordo com Bhatia (1997b), o conceito de propósito comunicativo, por sua versatilidade, atende a um considerável leque de variações entre gêneros relacionados e também dá conta da variação mais específica nas diferentes formas de realização de um gênero em particular. Desta forma, a variação na realização concreta dos gêneros só se tornaria distintiva ali onde ela estivesse indicando uma modificação substancial nos propósitos comunicativos. Ou seja, temos aqui o propósito comunicativo mantido como critério de identificação dos gêneros específicos.

\section{A QUESTÃO DO SUPORTE}

A discussão sobre o suporte dos gêneros textuais é, conforme Fraenkel (2004), recente nas ciências da linguagem, embora tenha sido conduzida no interior de outras disciplinas acadêmicas. No Brasil, se não no mundo, o primeiro linguista a dedicar um ensaio exclusivamente ao

BEZERRA - Gêneros introdutórios em ambiente virtual... 
assunto parece ter sido Marcuschi (2003), que se tornou referência obrigatória na questão.

Para Marcuschi (2003), a noção de suporte relaciona-se com a idéia de um "portador do texto", entendido como "um locus físico ou virtual com formato específico que serve de base ou ambiente de fixação do gênero materializado como texto" (2003, p. 11). O suporte se apresenta como um objeto, uma superfície (física ou virtual) que permite a manifestação concreta e visível do texto. Desse modo, o gênero provavelmente pode ser distinguido de seu suporte, na maioria das vezes, através da consideração de que o texto em si não deve ser confundido com um objeto físico. Assim, por exemplo, o outdoor é uma coisa, um objeto concreto, portanto, um suporte. O gênero, ou seja, o conteúdo suportado pelo outdoor, não é um objeto, mas um texto. É evidente que essa definição de suporte aplica-se preferencialmente ou talvez exclusivamente aos suportes de gêneros escritos. Extremamente problemática é a discussão do suporte no que tange aos gêneros da oralidade ou, no nosso caso, da escrita virtual.

Em que pese a dificuldade de identificação do suporte no que diz respeito aos gêneros digitais, não parece aconselhável descurar de sua importância. Nesse sentido, aplicam-se as palavras de Maingueneau (2001), para quem a relação entre gênero e suporte deve ser encarada com muita seriedade, já que hoje se torna cada vez mais necessário perceber e reconhecer que uma modificação no suporte do texto é capaz de modificar radicalmente o próprio gênero textual. Dessa forma, conclui Maingueneau: “O que chamamos 'texto' não é, então, um conteúdo a ser transmitido por este ou aquele veículo, pois o texto é inseparável de seu modo de existência material [bem como do seu modo de existência virtual, diríamos nós]: modo de suporte/transporte e de estocagem, logo, de memorização" (2001, p. 68).

$\mathrm{Na}$ relação com um suporte material, os textos impressos em particular se apresentam com a característica de ocupar um espaço concreto e determinado. Esse aspecto espacial se configura de maneira própria, por exemplo, no livro como suporte material de gêneros os mais diversificados. Essa configuração espacial possibilitará a associação entre os gêneros principais apresentados pelo livro e outros agrupamentos de gêneros, acrescidos como paratexto, para usar a terminologia proposta por Maingueneau (2001). No caso do livro acadêmico, os elementos 
paratextuais seriam entendidos como "o conjunto de fragmentos verbais que acompanham o texto propriamente dito" (MAINGUENEAU, 2001, p. 81). Esses "fragmentos", entretanto, variam desde a simples assinatura, título, data ou notas de rodapé até textos mais complexos, de extensão variável, tais como os prefácios e apresentações, entre outros. Uma questão central neste artigo é como ficam esses mesmos elementos quando "transmutados" (ou simplesmente transportados?) para um suporte digital.

$\mathrm{Na}$ ótica de Chartier (2002), a história da cultura escrita claramente estabelece uma forte vinculação entre "tipos de objetos" (suportes), "categorias de texto" (gêneros) e formas de leitura. Essas últimas são evidentemente afetadas e até determinadas pelas relações estabelecidas entre os dois primeiros elementos. Segundo o autor, a aludida vinculação se reflete, ao longo da história, em três inovações fundamentais. A primeira delas foi a invenção e adoção do códice entre os séculos II e IV da era cristã, com o consequente abandono do rolo e o surgimento do livro como objeto composto de folhas e páginas. A segunda inovação se dá no final da Idade Média, entre os séculos XIV e $\mathrm{XV}$, com o aparecimento do chamado "livro unitário", em que obras de um mesmo autor, em língua "vulgar", passam a ser veiculadas conjuntamente no mesmo suporte (livro) manuscrito. Por fim, na segunda metade do século XV, a invenção da imprensa viria possibilitar a rápida multiplicação e difusão das obras em suporte escrito (impresso).

Conforme Chartier (2002), essa "ordem dos discursos" transformou-se radicalmente com o advento da textualidade eletrônica, uma vez que o computador permite agrupar em um mesmo suporte e numa mesma forma de leitura gêneros completamente diferentes. Vale dizer, "cria-se assim uma continuidade que não mais diferencia os diversos discursos a partir de sua própria materialidade" (CHARTIER, 2002 , p. 23). Nesse contexto, a pergunta pela natureza dessa "transformação", bem como dessa "continuidade", torna-se mais que pertinente.

Assim, seja qual for o modo como se encara o suporte e sua relação com a constituição e apresentação dos gêneros, de toda forma uma teoria compreensiva não pode simplesmente continuar negligenciando a questão. Trata-se de não mais encarar de forma dicotômica a história e a constituição de gêneros e respectivos suportes, 
como se os últimos fossem "entidades cujas diferentes formas não alteram a estabilidade linguística e semântica", uma vez que "contra a abstração dos textos, é preciso lembrar que as formas que permitem sua leitura, sua audição ou sua visão participam profundamente da construção de seus significados" (CHARTIER, 2002, p. 62).

Neste trabalho, portanto, a noção de suporte desempenha um importante papel no esclarecimento das relações intrínsecas entre os gêneros introdutórios e os gêneros "centrais" para os quais eles apontam e os quais apresentam ou introduzem.

\section{UMA PROPOSTA DE ANÁLISE}

No quadro teórico da análise de gêneros de linha sociorretórica, um ponto de partida bem estabelecido inclui a identificação de movimentos e estratégias retóricas (moves e steps, no bem conhecido modelo proposto por Swales (1990), que tem sido usado, testado e modificado por diversos autores no Brasil e no exterior) e o emprego do conceito de propósito comunicativo como "critério privilegiado" (SWALES, 1990) ou como "ponto de chegada ao fim do círculo hermenêutico" (ASKEHAVE; SWALES, 2001), conforme discutido acima.

De acordo com a teoria de gêneros baseada em Swales (1990), o propósito comunicativo de um gênero é realizado através de um determinado número de moves (ou unidades retóricas, como o termo tem sido traduzido no Brasil), que são responsáveis por conferir ao gênero a sua "estrutura cognitiva típica" (BHATIA, 1993, p. 30). Nos termos de Swales (2004, p. 228), move é "uma unidade discursiva ou retórica que realiza, dentro do discurso escrito ou falado, uma função comunicativa coerente". Embora possa ser sinalizada por traços gramaticais, essa unidade retórica não se identifica necessariamente com um período gramatical, enunciado ou parágrafo claramente delimitados. Os moves são altamente "flexíveis em termos de sua realização linguística" (SWALES, 2004, p. 229).

Se o propósito comunicativo é realizado pelos moves ou unidades retóricas, estes, por sua vez, seriam realizados por diferentes estratégias 
retóricas, combináveis entre si. Swales (1990) denominou essas estratégias retóricas de steps. É precisamente assim que Askehave e Nielsen representam o que elas chamam de "modelo tradicional de análise de gêneros":

\begin{tabular}{|c||}
\hline $\begin{array}{c}\text { Propósito comunicativo } \\
\text { Realizado por }\end{array}$ \\
Estrutura de moves \\
Realizada por \\
Estratégias retóricas \\
\hline
\end{tabular}

Figura 1 - Teoria de gêneros tradicional (ASKEHAVE; NIELSEN, 2004, p. 4).

Percebendo a limitação desse modelo de análise de gêneros para dar conta dos gêneros digitais, até porque não foi desenhado para isso, Askehave e Nielsen (2004) propõem um "desafio à teoria de gêneros tradicional", na forma de uma ampliação do modelo original para um modelo bidimensional que se preste inclusive à elucidação do fenômeno da leitura em hipertexto.

A proposta de Askehave e Nielsen (2004) se assenta sobre uma premissa e acarreta uma implicação. A premissa é que a leitura de gêneros hipertextuais envolve dois modos distintos, alternáveis e nãoexcludentes: o "modo de leitura" e o "modo de navegação". A implicação é o deliberado rompimento com a velha dicotomia linear $x$ não-linear, ponto sempre discutido nos estudos de gêneros hipertextuais. Neste aspecto, as autoras seguem de perto as idéias de Finneman (1999), para quem a noção de alternância entre modos de acesso deve fazer parte da definição de hipertexto, primeiramente para que "se ajude a resolver o dilema da oposição entre texto e hipertexto" e segundo, porque o caráter opcional da relação entre os nódulos hipertextuais implica que "o usuário entra em uma relação metatextual com cada nódulo” (p. 29).

Dessa forma, ampliando o tradicional modelo swalesiano para que possa abranger a análise dos gêneros digitais, as autoras apresentam seu modelo "bidimensional" conforme a Figura 2: 


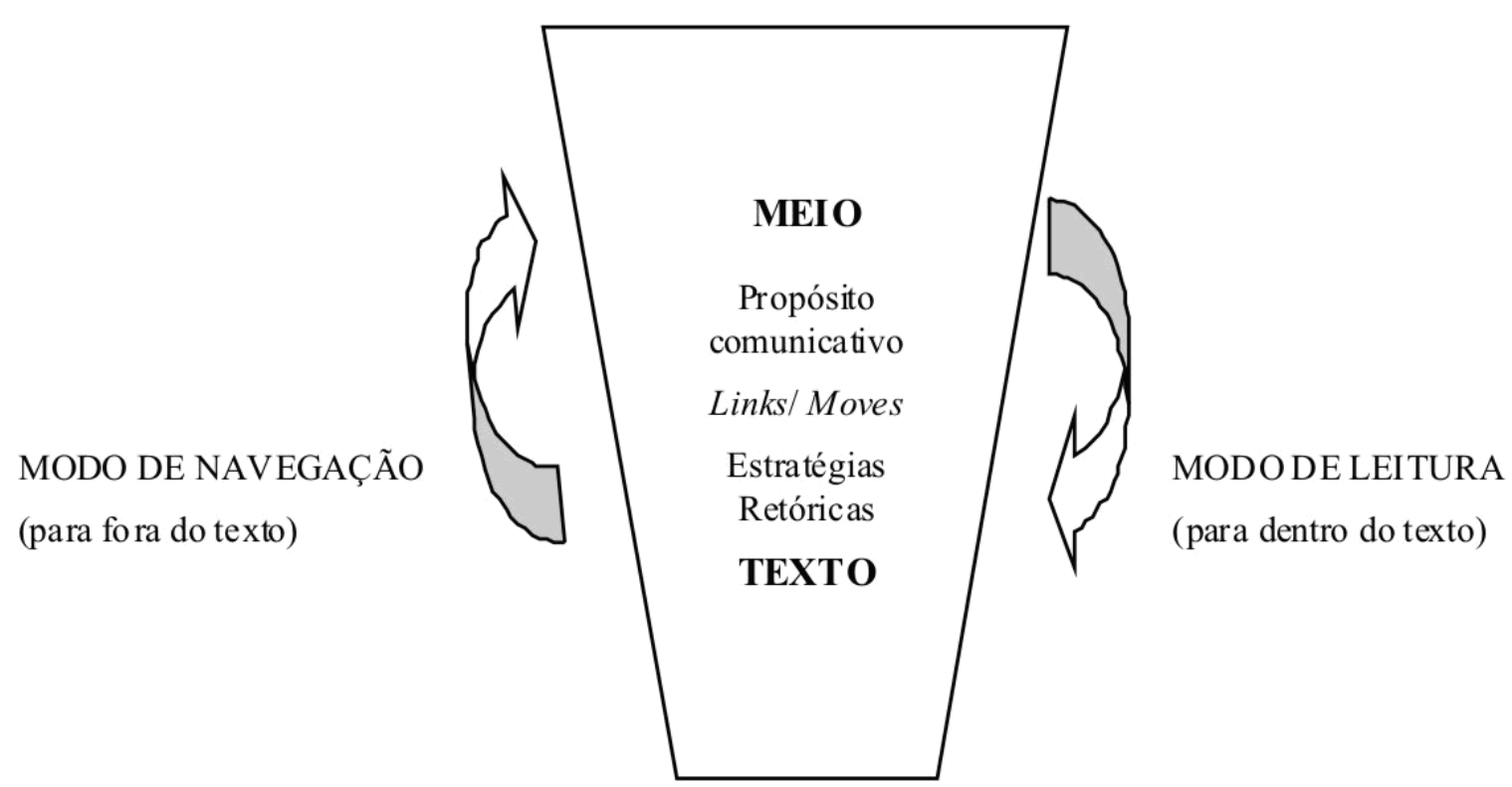

Figura 2 - Modelo bidimensional de gêneros (ASKEHAVE; NIELSEN, 2004, p. 17).

No modelo proposto, os elementos em destaque são o meio, neste caso, a web, e o próprio texto, que, de acordo com o modelo sociorretórico de análise de gêneros, baseado em Swales (1990), pode ser estudado levando-se em consideração três elementos distintos: (1) os propósitos comunicativos, que são realizados concretamente por meio de (2) moves ou movimentos retóricos, que por sua vez se realizam pelo uso de diferentes (3) estratégias (steps).

Para Askehave e Nielsen (2004), a forma tradicional do modelo configura o modo de leitura, ou "a leitura como tal", cujo movimento se dá do meio para o texto. Não teríamos, no modo de leitura, diferenças significativas entre ler um impresso ou ler uma tela de computador. Seria como ler o hipertexto não-hipertextualmente, por assim dizer. O interessante é que isso aponta para uma concepção não-essencialista de hipertexto. O hipertexto não é algo dado no mundo, mas o resultado de uma aproximação cognitiva, mais ou menos possibilitada pelas tecnologias utilizadas na exibição do texto.

Caberia então ao modo de navegação atender às características especiais do hipertexto. Neste caso, o ponto de partida é o texto, e o movimento do leitor se dá em direção ao meio, para fora do texto. Os propósitos comunicativos, consequentemente, serão realizados por meio 
dos biperlinks, e não mais por meio dos moves. Além disso, será mais apropriado, como se vê, falar de propósitos comunicativos sempre no plural, até porque estes passam a ser, mais claramente do que no suporte impresso, uma construção partilhada entre autor e leitor. Temos assim as linhas gerais da proposta de Askehave e Nielsen (2004) para a análise de gêneros digitais ${ }^{2}$, que nos leva necessariamente a uma discussão acerca da leitura em ambiente hipertextual.

\section{CONSIDERAÇÕES SOBRE A LEITURA EM HIPERTEXTO}

A discussão sobre a leitura em hipertexto feita por Askehave e Nielsen (2004) vem ao encontro de um intenso debate sobre o novo e o velho nessa matéria. Muitos e qualificados especialistas já se pronunciaram a respeito. Para citar um exemplo, lembro Marcuschi (2007, p. 148), que esclarece não ser "adepto da posição de que o hipertexto seja, em termos de atividades cognitivas, algo essencialmente novo". Parece-me que a distinção entre modo de leitura e modo de navegação, conforme exposta acima, nos permite concordar com a posição defendida pelo autor.

Se, como também ressalta Finnemann (1999), nem o autor está morto, pois pode, ao planejar seu (hiper)texto, vislumbrar caminhos possíveis para o leitor, nem o leitor é onipotente, pois haverá sempre limites para as possibilidades de exploração do hipertexto, é bem possível que devamos encarar o fenômeno hipertextual não só como tecnologia de construção de artefatos textuais, mas fundamentalmente como construção sociocognitiva.

Assim, parece claro que, num certo sentido, Koch estará certa quando afirma que "todo texto é um hipertexto" (KOCH, 2004 p. 61), embora essa afirmação pareça tão antipática e talvez reducionista para os estudiosos da área. O fato é que, em termos dos recursos tecnológicos hoje tipicamente associados ao hipertexto, encontramos textos dotados de diferentes graus de hipertextualidade. Temos, pois, um contínuo, e

\footnotetext{
2 Para uma exposição mais detalhada da proposta, com sua aplicação à análise do gênero homepage, ver Bezerra (2007).
}

BEZERRA - Gêneros introdutórios em ambiente virtual... 
não uma dicotomia entre hipertexto e não-hipertexto. Em última análise, porém, a leitura como atividade cognitiva terá o papel de atualizar ou não essas possibilidades hipertextuais, pois o hipertexto não poderá ser reduzido a uma propriedade imanente ao texto. O leitor sempre poderá aceitar, recusar ou subverter as propostas de leitura apresentadas pelo autor.

\section{PROCEDIMENTOS METOdOLÓGICOS}

Este estudo se insere no interior de um projeto de pesquisa que opera com um corpus composto por 50 exemplares de gêneros textuais introdutórios a livros acadêmicos em apresentação digital. O estudo representa uma ampliação de análise anterior desses mesmos gêneros em suporte impresso (o livro acadêmico), ancorada teoricamente em Bhatia (1997a, 2004) e exemplificada em profundidade em Bezerra (2006).

Entre os gêneros que costumeiramente introduzem livros acadêmicos, tais como prefácios, apresentações, introduções e sinopses, este último terá maior visibilidade no presente estudo, visto se tratar do gênero encontrado com mais frequência na divulgação de livros acadêmicos por meio da Internet.

O principal procedimento no estudo é a identificação de traços característicos da realização dos propósitos comunicativos tanto no modo de leitura como no modo de navegação. Não se buscou uma análise especialmente formal, mas uma análise do ponto de vista mais amplo das práticas sociais que definem o modo como um livro pode ser apresentado a possíveis leitores pela Internet. Trata-se, outrossim, de observações ainda preliminares, dada a ausência de pesquisas anteriores que se dediquem ao tema, de onde se depreende a necessidade de consolidar as investigações sobre o objeto em questão.

\section{ANÁLISE DOS GÊNEROS INTRODUTÓRIOS EM MEIO VIRTUAL}

Um fator que obviamente deve influir no funcionamento sociorretórico do gênero destinado a apresentar um livro ao potencial 
leitor será a presença ou ausência do livro em conexão com o referido gênero. Como demonstrado em Bezerra (2006, 2007), os gêneros introdutórios tipicamente são desprovidos de autonomia para circulação no meio social. Em princípio, não é plausível que um prefácio seja publicado em separado da obra a que se refere. No entanto, é o que acontece quando editoras e livrarias disponibilizam para consulta na web os mais diversos exemplares de gêneros introdutórios. Que fazer para suprir a ausência física do livro diante do potencial leitor?

O elemento central a atrair a atenção do leitor/navegador será, via de regra, a gravura da capa do livro, que tem uma função icônica, de representar o objeto a que se refere. A comunicação é acentuadamente multimodal. Desta forma, cria-se a ilusão, para o leitor, de que ele está como que manuseando o próprio objeto de seu interesse.

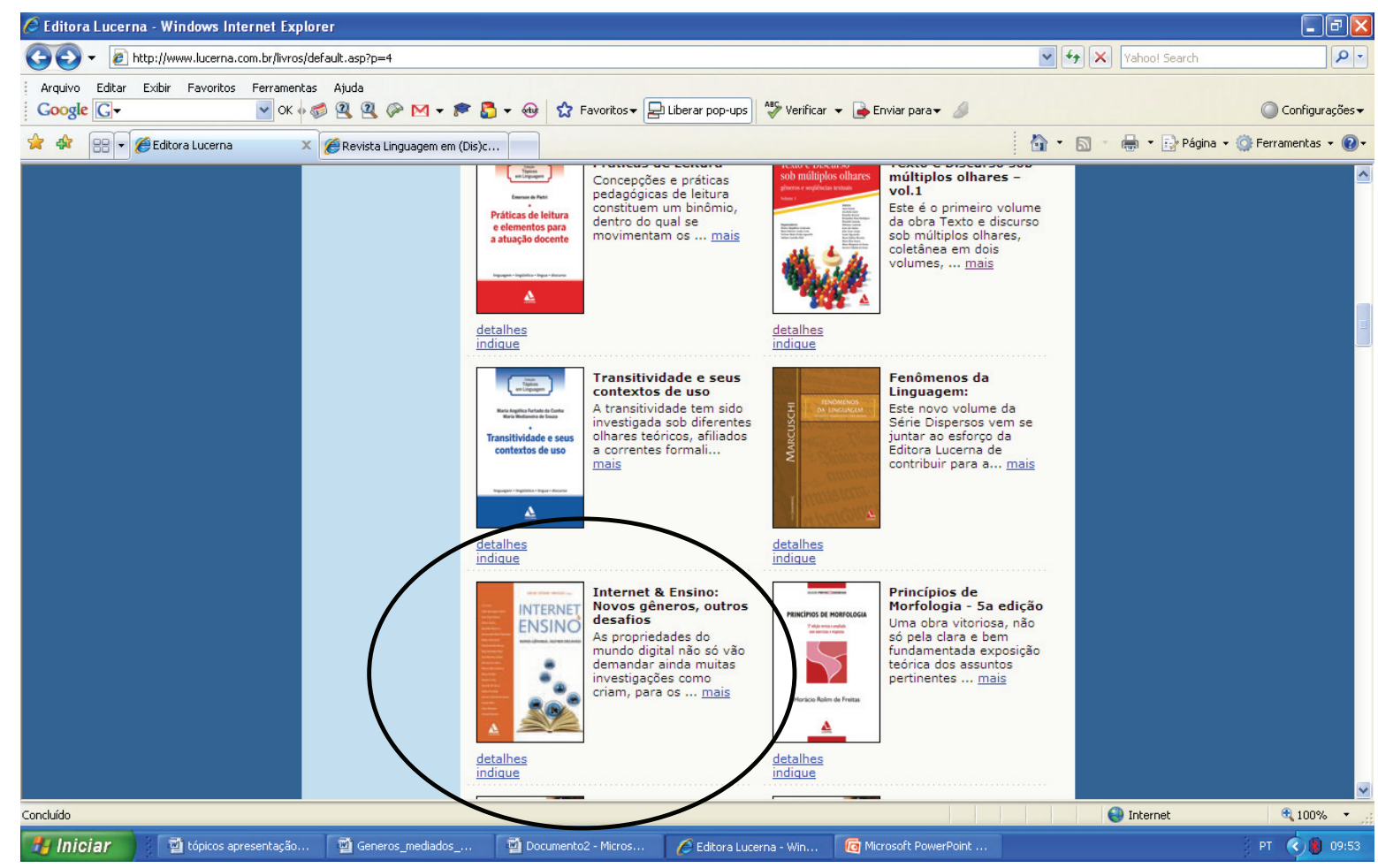

Figura 3 - A sinopse de livro como "aperitivo".

Contudo, nota-se que o propósito dessa primeira tela não esgota todos os possíveis propósitos comunicativos dos gêneros envolvidos. Temos aí algo semelhante a uma primeira página de jornal, em que os dizeres "As propriedades do mundo digital não só vão demandar ainda muitas investigações como criam, para os..." são seguidos de um hiperlink 
representado pela palavra mais. Diante de uma obra específica, portanto, o leitor dispõe de algumas opções: seguir ou não seguir o link mais para ler o restante da sinopse ou, ainda, optar pelos outros links disponíveis em relação com o livro (detalhes e indique).

Note-se que, em sua realização virtual, ao ser apresentada parcialmente como um "aperitivo" para o leitor, a sinopse funciona como um gênero introdutório não só do livro, mas introdutório de si mesma. É possível que a estranha segmentação do texto, terminando com o artigo "os..." incite o leitor/internauta a buscar o complemento do enunciado, navegando, portanto, de um nódulo A para um nódulo B.

Tanto o link mais como detalhes levarão o leitor a uma segunda tela, em que um leque maior de elementos retóricos se descortinará. Note que somente agora se tem acesso ao texto completo da sinopse, sempre acompanhado da gravura do livro. Entre outros elementos encontrados, são elencados todos os nomes dos colaboradores da obra, além de informações sobre as dimensões e número de páginas do livro. Procura-se dotar o leitor de todas as condições possíveis para tomar uma decisão.

Nesse ponto, teremos aspectos fundamentalmente distintos no que diz respeito aos propósitos comunicativos de uma sinopse, e nem todos eles poderão ser explicitados no espaço deste artigo. Basta lembrar, aqui, que o autor de uma obra, ou um convidado, ao escrever uma sinopse, dificilmente estará pensando em convencer um leitor-cliente, como é o caso das livrarias e editoras. É mais plausível que esse tipo de autor da sinopse estará concentrado de fato nos méritos que atribui à obra como produção acadêmica. É o que acontece também quando a sinopse se constrói a partir de recortes de outros gêneros encontrados no livro, tais como a apresentação ou o prefácio.

Porém, na situação comunicativa instaurada pelo site, os propósitos comunicativos do gênero são ressignificados e "comodificados" (FAIRCLOUGH, 1992) ou "colonizados" (BHATIA, 2004) pelo discurso promocional sinalizado, inter alia, pela indicação "compre também na...", bem como pelo insistente apelo para que o internauta "indique" o livro a um amigo. Veja-se, portanto, que o mesmo gênero de texto se presta à construção sociorretórico-discursiva de diferentes propósitos comunicativos, em nenhum momento imanentes 
ao texto. Essa constatação traz importantes implicações para a análise de gêneros "tradicional".

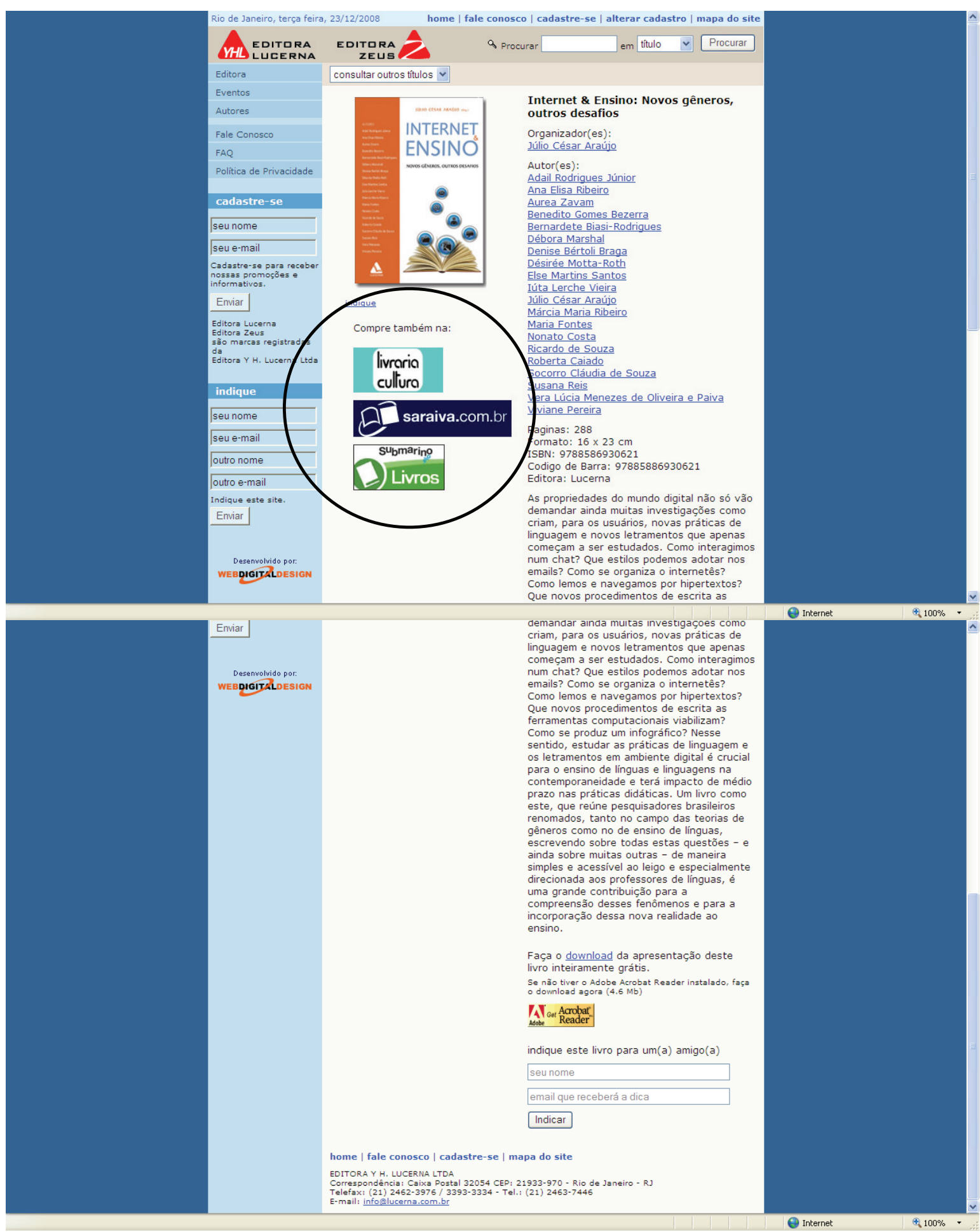

Figura 4 - Texto completo da sinopse.

BEZERRA - Gêneros introdutórios em ambiente virtual... 
A simulação online da presença física do livro inclui a disponibilização de outros gêneros introdutórios para a apreciação do leitor. A Figura 4 mostra um conjunto de elementos que inclui: como elementos mais visuais, a gravura da capa do livro e a foto da autora; como elementos tipicamente textuais, a sinopse, precedida do título do livro e nome da autora, e o gênero nota biográfica (cf. BEZERRA, 2006), também nomeado por alguns editores como "minicurrículo"; e como elementos mais evidentemente hipertextuais, os links que convidam o leitor a examinar sumário, introdução e as "orelhas do livro", além de links específicos para outras obras da autora.

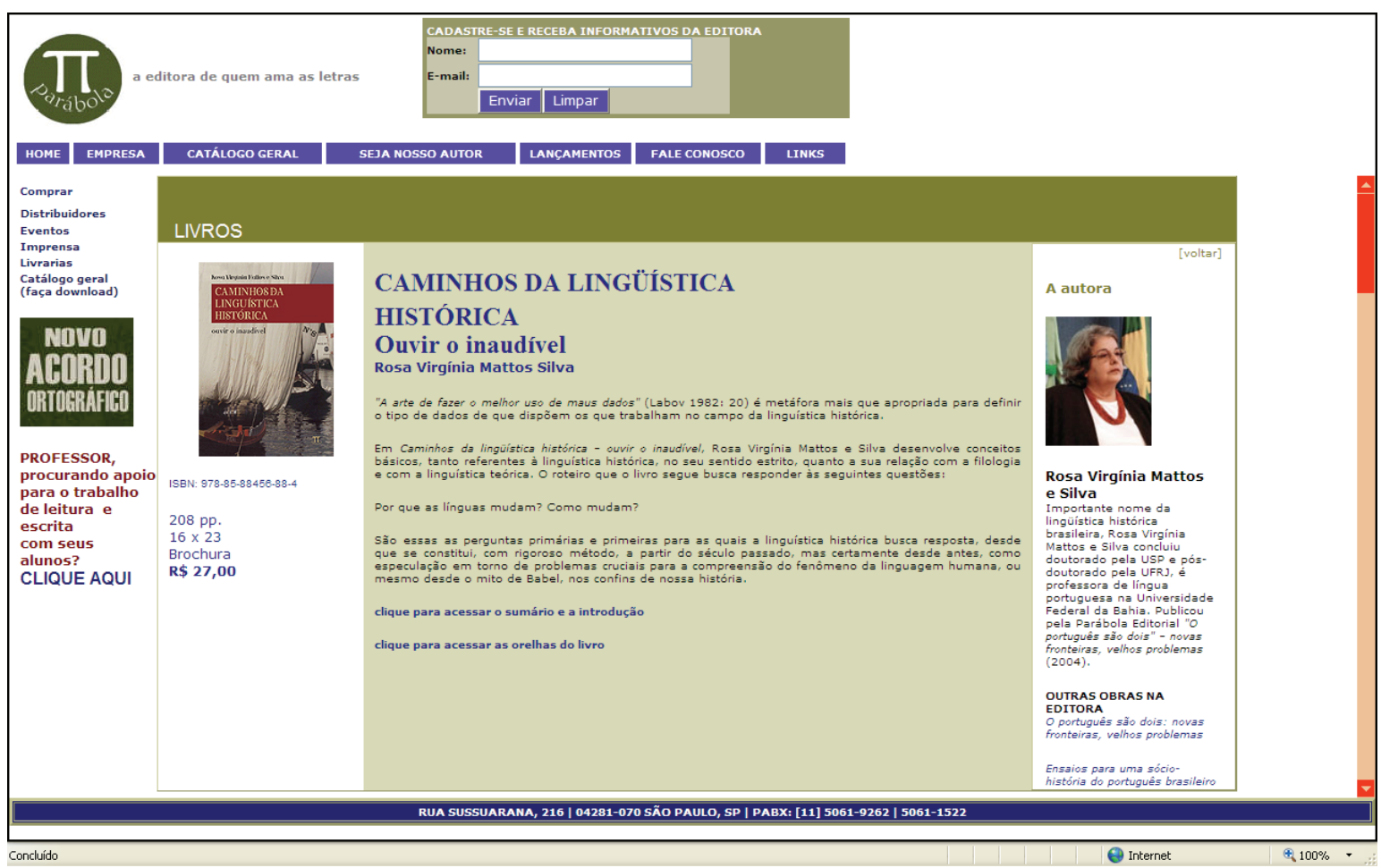

Figura 5 - Variedade de gêneros introdutórios em torno do livro acadêmico.

Assim, temos, neste caso, uma variedade significativa de gêneros textuais apresentados numa única tela, todos envolvidos de uma forma ou de outra com a promoção da obra aos olhos do leitor, potencial cliente.

Caso o leitor siga o link "clique para acessar o sumário e a introdução", ressaltado na tela pela cor diferenciada da fonte, será aberto um arquivo do tipo pdf (portable document format), em que, além dos 
prometidos sumário e introdução, encontram-se a reprodução da capa do livro e os dados técnicos da publicação, incluindo a ficha catalográfica, perfazendo um arquivo de 24 páginas no total.

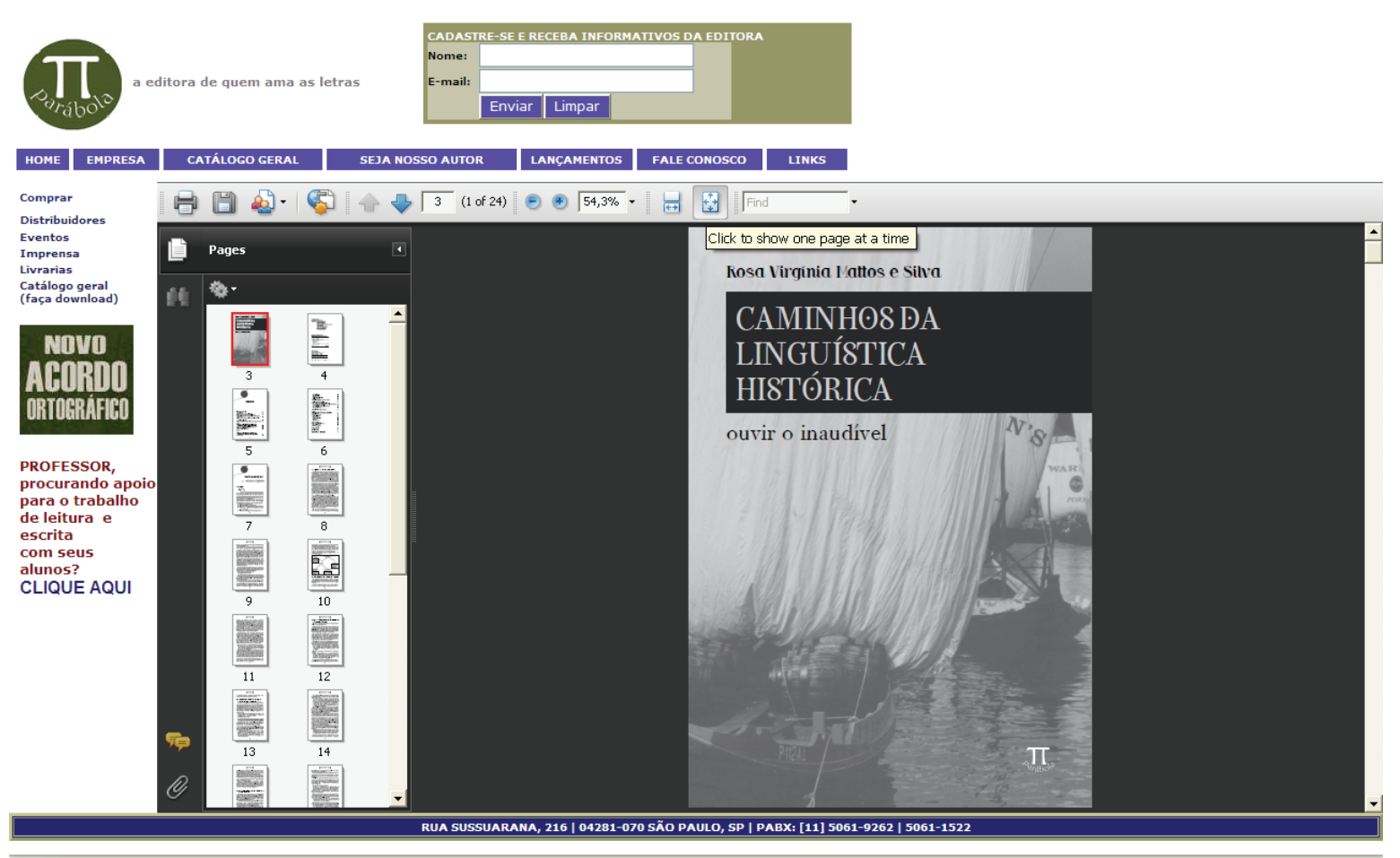

Figura 6 - Arquivo pdf contendo gêneros introdutórios.

Note-se que nos encontramos aí em pleno uso do modo de navegação, conforme proposto por Askehave e Nielsen (2004). O link em questão conduz o autor para um aplicativo fora dos domínios do navegador (browser), possibilitando-lhe inclusive salvar o arquivo sem nenhuma alteração de formato. Cabe ainda observar que a leitura do texto em pdf distingue-se da leitura em papel mais pelo suporte do que pelas possibilidades hipertextuais, não havendo diferenças significativas quanto à leitura em si: a paginação, o design, enfim, todas as características da obra em papel são conservadas. No arquivo pdf, apenas o modo de leitura será utilizado, de modo que a impressão em papel será um passo provavelmente adotado por um leitor que pretenda ler o arquivo completo.

BEZERRA - Gêneros introdutórios em ambiente virtual... 


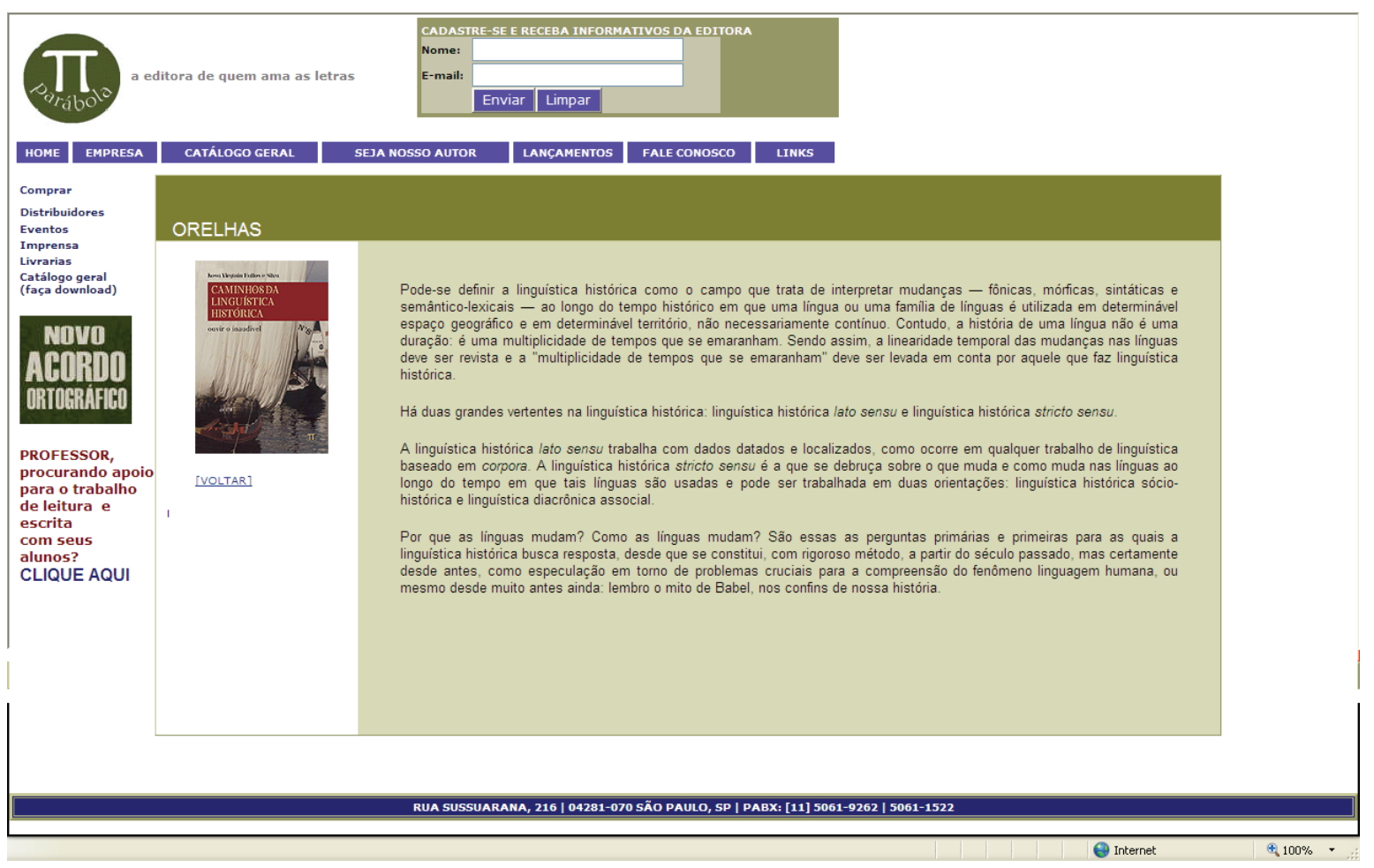

Figura 7 - "Orelhas" do livro no meio virtual.

Quanto ao link "clique para acessar as orelhas do livro", surpreendentemente leva apenas ao texto das orelhas do livro, inclusive em formato html (bypertext markup language), o que se explica pela menor extensão do texto se comparado à introdução. Note-se, de passagem, a nomeação do texto por recurso ao livro como suporte material. Em princípio, no hipertexto só é possível falar de "acessar as orelhas do livro" analógica ou metaforicamente. ${ }^{3}$

\section{REDISCUTINDO GÊNEROS INTRODUTÓRIOS VIRTUAIS E PROPÓSITOS COMUNICATIVOS}

A análise apenas brevemente esboçada neste artigo permite uma fecunda reflexão sobre gêneros e propósitos comunicativos, tendo como aspecto-chave, na comparação com esses mesmos gêneros quando apresentados em papel, a noção de suporte. É claro que a introdução do

\footnotetext{
${ }^{3}$ Mesmo na análise de gêneros no livro impresso, convencional, não é possível falar de "orelhas" como gênero, e sim como suporte físico ou, mais precisamente, como uma parte específica do livro como suporte material.
} 
novo suporte, neste caso, levanta ainda a pergunta por quem está usando o suporte para realizar os gêneros. O responsável institucional pela veiculação dos gêneros introdutórios em questão determina, neste caso, sua inserção num domínio misto entre academia e marketing, com acentuado peso para este último.

Não é fundamentalmente o conteúdo dos textos que sozinhos determinam sua identificação como acadêmicos ou promocionais, e sim o contexto de práticas sociais em que são inseridos. Em tese, alguém poderia produzir esses gêneros e publicá-los com intenção "meramente" acadêmica, mas o fato é que, em nossa sociedade, quem faz isso são empresas interessadas em vender o livro encarado como produto, de modo que fica bastante obscurecido o caráter acadêmico intrínseco aos gêneros introdutórios, ainda que possam ter sido estes que determinaram originalmente a produção dos textos.

Do ponto de vista do conteúdo, nada muda nos gêneros introdutórios em meio digital, uma vez que a versão digital apenas reproduz, nesse aspecto, a versão impressa. A grande novidade está no modo de apresentação no novo suporte, que de alguma forma instaura uma nova situação comunicativa.

Os propósitos comunicativos serão, consequentemente, diversificados de acordo com a situação dos atores sociais envolvidos na troca (produção e recepção) dos textos. Do ponto de vista do autor que prepara ou convida alguém a preparar uma sinopse ou apresentação para a obra, o propósito deverá estar relacionado com uma apresentação (positiva) de caráter acadêmico. Do ponto de vista do editor, que por vezes também é responsável especialmente pelo texto da sinopse, o propósito já pode ter em mente a apresentação do livro como produto para venda. Uma vez exposto no site, o texto agora se coloca numa outra situação, decididamente voltada para a sedução do leitor como cliente. Os propósitos, em função do contexto de uso, se modificam sensivelmente.

\section{CONSIDERAÇÕES FINAIS}

Neste artigo, meu objetivo foi rediscutir o conceito de propósito comunicativo no contexto da análise de gêneros textuais realizados em

BEZERRA - Gêneros introdutórios em ambiente virtual... 
meio digital. O estudo reafirma a complexidade do conceito, especialmente quando se trata da tentativa de identificação a priori dos propósitos de um gênero qualquer. A respeito dessa dificuldade já alertavam Askehave e Swales (2001) ao discutirem o assunto.

De alguma forma, o meio virtual, aliado ao contexto de práticas sociais em que se usam os gêneros introdutórios relacionados com livros acadêmicos, intensifica a fluidez dos propósitos comunicativos. Se, no suporte impresso, já não era simples descrever gêneros como introdução, prefácio, sumário, nota biográfica ou sinopse como estritamente acadêmicos, no meio virtual isso se torna impraticável. O contexto em que os livros são apresentados nos sites de editoras e livrarias, páginas eletrônicas que parcialmente simulam (ou transmutam) os tradicionais catálogos impressos, praticamente institui um olhar para o livro como produto de venda. Nesse contexto, os motivos por que alguém folhearia um livro no formato tradicional se reduzem a praticamente um único motivo: comprar ou não comprar.

O leque de gêneros disponibilizados para o exame por parte do leitor chega a se comparar ao que acontece no livro impresso. Gêneros de maior extensão, retirados do miolo do livro, têm conservada a formatação própria do impresso, inclusive paginação e design. Os gêneros localizados nas orelhas ou na quarta capa (sinopse e nota biográfica, no mais das vezes), por sua vez, recebem uma formatação nova no formato html, típico da rede www.

Como foi dito anteriormente, a sinopse é de longe o gênero de maior visibilidade quando se trata dos gêneros introdutórios em meio digital. Na prática, ela se torna uma espécie de porta de entrada para outros gêneros que poderão ser disponibilizados. Em torno dela é que se organizam todos os links propostos ao leitor, de modo que esse gênero ganha admirável centralidade e destaque quando se trata de introduzir um livro em ambiente virtual. Na modalidade impressa, é improvável que a sinopse tenha essa proeminência entre os outros gêneros introdutórios.

Em suma, essas poucas observações poderão nos ajudar a perceber cada vez mais a importância e a necessidade que temos de sair das primeiras impressões sobre o uso da linguagem no domínio virtual, reduzidas muitas vezes a considerações alarmistas sobre o "perigo" da 
escrita na Internet, em especial a escrita produzida por adolescentes e jovens em suas práticas interacionais mediadas pelo computador.

$\mathrm{Na}$ pesquisa de gêneros textuais, particularmente, há uma urgente necessidade de buscar um equilíbrio nos esforços de análise, de modo a se contemplar tanto a escrita tradicional como a fala e, agora, a escrita produzida no interior das práticas comunicativas desenvolvidas na web. Tudo isso, afinal, deverá resultar em respostas para as questões abertas no ensino, acarretando, como previu Marcuschi (2007, p. 168), "redefinições curriculares, revisão e identificação de fontes".

\section{REFERÊNCIAS}

ASKEHAVE, I.; NIELSEN, A. E. Web-mediated genres: a challenge to traditional genre theory. Working papers, Denmark, Aarhus School of Busness, n. 6, p. 1-50, 2004.

; SWALES, J. M. Genre identification and communicative purpose: a problem and a possible solution. Applied linguistics, v. 22, n. 2, p. 195-212, 2001.

ATKINSON, D. Scientific discourse in sociohistorical context: the philosophical transactions of the Royal Society of London, 1675-1975. Mahwah, New Jersey: LEA, 1999.

BAKHTIN, M. M. Os gêneros do discurso. In: Estética da criação verbal. 2. ed. São Paulo: Martins Fontes, 1997 [1953]. p. 279-326.

BEZERRA, B. G. A distribuição das informações em resenhas acadêmicas. 2001. 141f. Dissertação (Mestrado em Linguística) - Programa de Pós-graduação em Linguística, Universidade Federal do Ceará, Fortaleza, 2001.

Gêneros introdutórios em livros acadêmicos. 2006. 256f. Tese

(Doutorado em Linguística) - Programa de Pós-graduação em Letras, Universidade Federal de Pernambuco, Recife, 2006.

Gêneros introdutórios mediados pela web: o caso da homepage. In:

ARAÚJO, J. C. (Org.). Internet e ensino: novos gêneros, outros desafios. Rio de Janeiro: Lucerna, 2007. p. 113-125.

BHATIA, V. K. Analysing genre: language use in professional settings. London: Longman, 1993.

BEZERRA - Gêneros introdutórios em ambiente virtual... 
. Genre-mixing in academic introductions. English for specific purposes, v. 16, n. 3, p. 181-195, 1997a.

. Genre analysis today. Revue Belge de Philologie et d'Histoire, v. 75 , n. 3, p. 629-652, 1997 b.

. Worlds of written discourse: a genre-based view. London:

Continuum, 2004.

CHARTIER, R. Os desafios da escrita. São Paulo: Ed. UNESP, 2002.

FAIRCLOUGH, N. Discurso e mudança social. Brasília: Ed. UnB, 2001 [1992].

FINNEMANN, N. O. Hypertext and the representational capacities of the binary alphabet. 1999. Disponível em: <www.hum.au.dk/ckulturf/pages/ publications/nof/hypertext.htm>. Acesso em: 23 dez. 2008.

FRAENKEL, B. Suporte de escritura. In: CHARAUDEAU, P.;

MAINGUENEAU, D. (Org.). Dicionário de análise do discurso. São Paulo: Contexto, 2004. p. 461-462.

JOHNS, A. Text, role, and context: developing academic literacies.

Cambridge: Cambridge University Press, 1997.

KAY, H.; DUDLEY-EVANS, T. Genre: what teachers think. ELT journal, Oxford, v. 52, n. 4, p. 308-314, out. 1998.

KOCH, I. G. V. Introdução à linguística textual: trajetória e grandes temas. São Paulo: Martins Fontes, 2004.

MAINGUENEAU, D. Análise de textos de comunicação. São Paulo: Cortez, 2001.

MARCUSCHI, L. A. A questão do suporte dos gêneros textuais. DLCV: língua, linguística e literatura, João Pessoa, v. 1, n. 1, p. 9-40, out. 2003. . Linearização, cognição e referência: o desafio do hipertexto. In: . Cognição, linguagem e práticas interacionais. Rio de Janeiro: Lucerna, 2007. p. 146-170.

MARTIN, J. R. Language, register, and genre. In: CHRISTIE, F. (Ed.). Children writing: reader. Geelong, Australia: Deakin University Press, 1984.

MILLER, C. R. Genre as social action. In: FREEDMAN, A., MEDWAY, P. (Ed.). Genre and the new rhetoric. London: Taylor \& Francis, 1994 [1984]. p. 23-42. 
SWALES, J. Genre analysis: English in academic and research settings. Cambridge: Cambridge University Press, 1990.

Research genres: exploration and applications. Cambridge:

Cambridge University Press, 2004.

Recebido em 25/01/09. Aprovado em 11/07/09.

Title: Introductory genres in virtual settings: a (re) analysis of communicative purposes

Author: Benedito Gomes Bezerra

Abstract: In this paper we re-examine the concept of communicative purpose, derived from socio-rhetorical genre analysis, and apply it to the study of introductory genres of academic books presented in digital form. The research, which is theoretically based on Swales (1990, 2004), Bhatia (1997a, 2004) and Bezerra (2006), investigates a corpus of 50 exemplars of digital introductory genres collected from sites of publishing companies and specialized bookstores. The results show that when moved from the printed mode to a virtual support, these genres face visible transformations in terms of communicative purposes. In particular, the typical academic discourse used in these genres tends to make room to a strongly marked promotional discourse, characterizing a process of colonization of genres by other genres and discourses (BHATIA, 2004).

Keywords: introductory genres; hypertext; communicative purpose.

Titre: Genres d'introduction en milieu virtuel: une (ré)analyse des propos communicatifs

Auteur: Benedito Gomes Bezerra

Résumé: Dans ce travail, on fait une nouvelle analyse du concept de propos communicatif, venu de l'analyse de genres de ligne socio-rhétorique, en s'appuyant sur les genres d'introduction des livres académiques faits en milieu digital. La recherche, fondée théoriquement chez Swales (1990, 2004), Bhatia (1997a, 2004) et Bezerra (2006), fait l'investigation d'un corpus de 50 exemplaires de genres d'introduction digitaux obtenus dans des sites des maisons d'édition et librairies spécialisées. Les résultats démontrent que les genres en question, quand ils sont transposés du moyen imprimé au support virtuel, traversent des transformations sensibles dans leurs propos communicatifs. En particulier, le discours académique typique de ces genres a la tendance à faire place à un discours remarquablement promotionnel, caractérisant un procès de colonisation de genres par d'autres genres et discours. (BHATIA, 2004).

Mots-clés: hypertexte; genre d'introduction; propos communicative.

Título: Géneros introductorios en ambiente virtual: un (re) análisis de los propósitos comunicativos

Autor: Benedito Gomes Bezerra

Resumen: En este trabajo, reexaminamos el concepto de propósito comunicativo, oriundo del análisis de géneros de línea socio-retórica, teniendo en cuenta los géneros

BEZERRA - Gêneros introdutórios em ambiente virtual... 
introductorios de libros académicos realizados en medio digital. La pesquisa, fundamentada teóricamente en las obras de Swales (1990, 2004), Bhatia (1997a, 2004) y Bezerra (2006), investiga un cuerpo de 50 ejemplares de géneros introductorios digitales recogidos de sitios de editoras y librerías especializadas. Los resultados muestran que los géneros en cuestión, al ser transportados del medio impreso para el soporte virtual, pasan por sensibles transformaciones en sus propósitos comunicativos. Particularmente, el discurso académico típico de esos géneros tiende a dar lugar a un discurso marcadamente promocional, caracterizando un proceso de colonización de géneros por otros géneros y discursos (BHATIA, 2004).

Palabras-clave: hipertexto; género introductorio; propósito comunicativo. 